\title{
Percepções daqueles que perguntam: - qual a sua cor?
}

Perceptions of those who ask: - what is your color?

Jaqueline Grandi', Miriam Thais Guterres Dias², Simone Glimm³

${ }^{1}$ Residência Integrada em Saúde Coletiva pela Escola de Saúde Pública (ESP) - Porto Alegre (RS), Brasil.

jaquegrandi@gmail.com

${ }^{2}$ Doutora em Serviço Social pela Pontifícia Universidade Católica do Rio Grande do

Sul (PUCRS) - Porto Alegre (RS), Brasil.

Professora e pesquisadora da UFRGS.

miriamtgdias@gmail.com

${ }^{3}$ Especialista em Ciência da Saúde pela Escola de Saúde Pública (ESP) - Porto

Alegre (RS), Brasil. Tutora do Programa de Residência Integrada em Saúde da Escola de Saúde Pública (ESP) - Porto Alegre (RS), Brasil.

sglimm@ig.com.br.
RESUMO: Este artigo relata os resultados de pesquisa-ação pautada na Política de Saúde Integral da População Negra, realizada com o objetivo de instrumentalizar trabalhadores de um serviço de saúde de atenção básica da Secretaria Municipal de Saúde de Porto Alegre. Existem poucos estudos acerca dessa Política, que ainda é um importante meio de afirmação da inclusão social e enfrentamento à discriminação. Ao colaborar com a qualificação dos processos de trabalho de equipe de serviço de saúde, a pesquisa se propôs a auxiliar na operacionalização dos trabalhos do SUS e contribuir para uma sociedade mais igualitária e equânime, onde os sujeitos tenham seus direitos garantidos.

PALAVRAS-CHAVE: SUS; Política de saúde da população negra; Etnia; Atenção básica em saúde; Pesquisa-ação.

ABSTRACT: This article reports the results of an action research based on the Integral Health Policy of the Black Population conducted with the aim of providing knowledge to basic healthcare workers of the Municipal Health Secretariat in the city of Porto Alegre. There are few studies about this Policy, which is still an important means of social inclusion acknowledgement and discrimination tackling. By collaborating with the qualification of the health service teamwork processes, the research sets out to assist in the operationalization of SUS' works and contribute to a more egalitarian and fair society, where the subjects have their rights guaranteed.

KEYWORDS: SUS; Health policy of black population; Ethnicity; Primary health care; Action research. 


\section{Introdução}

A discussão acerca da temática etnia ganhou força nas últimas décadas no Brasil em estreita relação com ações adotadas pelo governo federal no final da década de 1990 e nos anos 2000, período marcado pelo crescimento da consciência pública sobre as desigualdades raciais. Esse movimento criou as condiçóes necessárias para que se pense o tema etnia e sua interface com as diversas políticas públicas.

Escolher a Política de Saúde Integral da População Negra (PSIPN) como tema de pesquisa tem relação com essa conjuntura, considerando a necessidade de discutir o assunto e de contribuir para a capacitação das equipes de saúde da família, i.e., dos trabalhadores inseridos nos serviços de Atenção Básica em Saúde do Sistema Único de Saúde (SUS). O serviço de saúde desta pesquisa - doravante denominado ESF - localiza-se em uma comunidade do bairro Partenon em Porto Alegre e conta com uma população composta por diversas etnias, incluindo um número significativo de moradores pardos e negros. De acordo com o Plano Municipal 2010-2013 da Prefeitura Municipal de Porto Alegre, as três regiōes com a maior concentração de população negra no município de Porto Alegre são Partenon e Lomba do Pinheiro, 27,2\%, seguidas da Região Leste Nordeste, 27,1\%, e da Restinga, 26,4\% (PORTO ALEGRE, 2010).

É característico dessa região o grande número de terreiros, que são também espaços de produção de saúde e de cuidado na tradição das religióes de matriz africana. Por essa razão, em 2010, a ESF aceitou o convite da Comunidade Terreira Ilê Asé Iyemonjá Omi Olodô, integrante da Rede Nacional de Religióes AfroBrasileiras e Saúde (RENAFRO), para participar das reuniōes denominadas 'Conversa Afiada'. Nessa oportunidade, foram realizadas rodas de conversa com a proposta de estabelecer uma parceria para "[...] melhorar a qualidade de vida dos usuários do território adscrito, garantindo a efetivação dos princípios de equidade, acessibilidade e respeito à diversidade e fortalecimento do SUS” (KERKHOFF; FOLA, 2012, p.118). Essa ação resultou na aproximação entre a ESF e o terreiro, no intuito de reafirmar o respeito às crenças e costumes.
Percebe-se, assim, uma oportunidade para que se discuta o tema etnia, considerado como proposição da pesquisa.

Outra premissa considerada é a necessidade de os serviços de saúde conhecerem as reais demandas e especificidades da população atendida para que tenham condiçóes de oferecer atendimento integral que contemple uma noção de saúde ampliada. Esta pesquisa teve como objetivos: conhecer e explicitar os elementos da PSIPN a fim de instrumentalizar os trabalhadores da unidade e contribuir para uma futura implementação dessa Política nesse serviço de saúde; conhecer suas diretrizes e seus objetivos; mapear junto à equipe da unidade de saúde seus principais aspectos para conhecer suas potencialidades e possíveis lacunas; valorizar e congregar os conhecimentos dos membros dos movimentos sociais de defesa de direitos da população negra de Porto Alegre; e considerar os conhecimentos acerca da PSIPN advindos dos gestores de saúde, identificando as principais dificuldades manifestadas pelas equipes de saúde durante o processo de realização da pesquisa.

A seguir, apresentam-se e discutem-se os resultados alcançados pela pesquisa. Inicia-se por um breve resgate do processo de integração dos negros na sociedade brasileira e segue-se apresentando a proposta para a equipe de um serviço de saúde de atenção básica e construindo o projeto de pesquisa. Relata-se a forma como ocorreu a implementação da proposta na ESF - por meio de etapas vivenciadas no coletivo - e finaliza-se com a análise das reflexões produzidas pelos trabalhadores da ESF durante a pesquisa, além de algumas consideraçóes. Importa salientar que se trata de um estudo inovador em virtude da perspectiva de construção coletiva, viabilizado por pesquisa-ação envolvendo trabalhadores do SUS que refletiram e participaram ativamente de todo o processo, em consonância com o método escolhido.

\section{A população negra na sociedade brasileira}

Para iniciar a discussão aqui proposta, cabe introduzir breve resgate histórico acerca da integração da população negra na sociedade brasileira. 
A integração dos negros na sociedade de classes, título dado a um dos livros de Florestan Fernandes (2000), é tema de estudos que mostram as dificuldades que essa população enfrentou ao buscar inserção social. Essa integração teve como marco principal a abolição da escravatura, fato que ocorreu como ação isolada, posto que não foram criadas as condiçôes para uma real inserção social. Essa falta de condiçôes, ou seja, o não acesso à moradia, saúde, educação, a emprego, gerou forte repercussão negativa. Ao falar do período de industrialização do País do início do século XX e tomando por base a cidade de São Paulo, Fernandes ressalta a exclusão social sofrida por negros e mulatos que, "viveram dentro da cidade, mas não progrediram com ela e através dela" e, nesse contexto, "agravou-se, em lugar de corrigir-se, o estado de anomalia social transplantado do cativeiro" (FERNANDES, 2008, p.119).

Por volta de 1889, já era evidente a incapacidade do Estado em promover açóes de ampliação de oportunidades para a população negra, no momento em que estava em mudança o status jurídico dessa população, considerando o fim da economia escravocrata. A naturalização das desigualdades teve apoio na consolidação da teoria racista - entre 1880 e 1920 -, que reafirmava a existência de uma hierarquia racial e o reconhecimento dos problemas resultantes de uma sociedade multirracial (JACCOUD, 2008). Essa ideologia sustentou-se mesmo com a mudança de contexto social e jurídico da população negra, somada à "ideia de que a miscigenação permitiria alcançar a predominância da raça branca" (JACCOUD, 2008, p.49).

Assim, surge no Brasil a 'tese do branqueamento' como projeto nacional, que se sustentava em uma 'preferência' à mestiçagem e aos 'povos mestiços', reconhecendo relativa aceitação da sociedade daquela época do grupo identificado com mulatos, pois teriam a possibilidade de continuar em uma trajetória em direção ao ideal branco. Amparada nessa 'tese de branqueamento', vigorou a ideia de que o progresso do País estaria atrelado não somente ao desenvolvimento econômico como também a um aprimoramento racial do povo. Corrobora para essa noção a constituição do cientificismo como verdade absoluta, posto que, ainda no século XVIII, alguns autores desenvolviam teses cientificas que afirmavam a inferioridade racial do negro (RODRIGUES, 2012). Esse contexto influenciou a tomada de decisóes políticas que contribuíram para a restrição de possibilidades de integração da população negra na sociedade brasileira, aprofundando as desigualdades presentes até os dias atuais.

A exclusão social dessa etnia teria tido sua significação reduzida com a migração das outras etnias que também buscavam integração na sociedade capitalista. Assim, surge uma nova configuração referente ao mercado de trabalho, onde o processo de industrialização cria a necessidade de trabalhadores com capacidade de venda de sua força de trabalho; os negros e mulatos não estavam nesta categoria, sendo considerados inaptos para a aprendizagem técnica ou com capacidade insuficiente para o trabalho na indústria, participando em proporções ínfimas (FERNANDES, 2008).

Destarte, a ausência de oportunidades de inserção resultou na permanência da população negra em condiçōes sociais desfavoráveis frente a outros segmentos populacionais. Nas décadas seguintes ao início do século XX, não houve proposta do Estado para resolver ou minimizar tal problemática, estando os reflexos desse período histórico ainda presentes na sociedade contemporânea. Dados da Secretaria Especial de Políticas de Promoção da Igualdade Racial (SEPPIR), que compóem a Política Nacional de Saúde Integral da População Negra (BRASIL, 2007), trazem elementos que comprovam a intensidade da desigualdade no Brasil. No campo da educação, o índice brasileiro de analfabetismo geral era de 12,4\%, em 2001: entre os negros, a proporção era 18,2\% e, entre os brancos, 7,7\% (IPEA 2002 apud BRASIL, 2007, p.25). Quanto ao aspecto da pobreza, mais de 32 milhóes de negros com renda de até $1 / 2$ salário mínimo viviam, em sua maioria, em lugares com características indesejáveis de habitação e eram potencialmente demandantes de serviços de assistência social (IBGE, 2000; IPEA 2002 apud BRASIL, 2007, p.26).

Segundo informaçóes que integram o caderno Comunicados do IPEA (n.91, 2011), 97 milhóes de pessoas se declararam negras - pretas ou pardas - no Censo Demográfico de 2010, e 91 milhões, brancas. Esse documento revela as características demográficas 
da população negra do Brasil e traça um paralelo entre as condiçôes de vida das populações branca e negra, informando que a população negra é predominante, mais jovem e mais pobre, tem mais filhos e está mais exposta à mortalidade por causas externas, especialmente homicídios (IPEA, 2011).

Esses indicadores demonstram uma relação importante entre as condiçóes de vida e a necessidade de políticas públicas sociais que sejam capazes de contribuir de forma significativa para a superação de lacunas resultantes do não acesso aos serviços e da negação de direitos humanos. Portanto, justifica-se a necessidade de qualificar os trabalhadores do SUS para a implementação de uma política de saúde específica que atenda às necessidades de uma população com um histórico particular e diferenciado das demais etnias no Brasil.

\section{Metodologia}

A pesquisa realizada propôs um estudo participante calcado na realização de encontros sistemáticos em datas acertadas com as duas equipes de trabalho de uma ESF: duas enfermeiras, quatro técnicas em enfermagem, dois médicos, uma dentista, uma técnica em saúde bucal e seis residentes da Escola Pública de Saúde do RS de diferentes profissóes. $\mathrm{O}$ intuito era o de informar e instigar a reflexão e troca de conhecimento, em parceria com movimentos sociais de defesa dos direitos da população negra de Porto Alegre e representantes da Secretaria da Saúde no âmbito da implementação da política social pública em questão. A metodologia adotada se norteia no método pesquisa-ação, que, segundo Michel Thiollent ocorre [...] "quando houver realmente uma ação por parte das pessoas ou grupos implicados nos problemas em observação" (THIOLLENT, 2002, p.15).

O método escolhido implicou um movimento que se inicia pela prática, continua com a compreensão e em seguida passa para a explicação, retornando, então, à prática. A prática referida é a prática social do grupo em primeiro lugar e, em segundo, a prática do pesquisador. Elas se misturam, resultando em conhecimento para o grupo e também para o pesquisador (HAGHETTE, 1992).
$\mathrm{Na}$ fase exploratória da pesquisa, que consistiu em 'descobrir o campo de pesquisa, os interessados e suas expectativas em estabelecer um primeiro levantamento da situação, dos problemas prioritários e de eventuais açóes' (THIOLLENT, 1988), realizou-se uma conversa com a equipe participante a fim de construir uma abordagem coletiva sobre o tema. Para tanto, a pesquisadora apresentou uma proposta de pesquisa em reunião de equipe e a conversa inicial resultou na aprovação da metodologia sugerida, do número de encontros em que se abordaria o tema e da aceitação dos objetivos geral e específicos considerados pertinentes pelo grupo.

Ainda na fase exploratória, levaram-se em conta as características do território, conforme dito anteriormente, especialmente com relação às características étnicas da população, com o objetivo de dar continuidade às açóes já realizadas, como as rodas de conversa propostas pela RENAFRO. Assim, pensando em se atingir os objetivos traçados, aprovou-se a proposta de participação das duas equipes da ESF neste estudo. A pesquisa baseou-se no Plano Municipal de Saúde 2010-2013 de Porto Alegre, na Constituição Federal de 1988 e nas próprias Políticas Nacional e Estadual de Saúde Integral da População Negra.

Respeitando o método escolhido, que prevê um trabalho integrado entre pesquisador e participantes, seguiu-se o cronograma definido conjuntamente para a realização de quatro encontros de uma hora e meia na própria ESF. Dois desses encontros foram restritos à equipe e à pesquisadora; um com a participação de gestores da política de saúde e outro com a presença de representantes dos movimentos sociais de defesa dos direitos da população negra.

$\mathrm{O}$ primeiro encontro contou com a presença do representante atual da gestão federal da política de saúde, Sr. Stênio Dias Pinto, Chefe do Serviço de Auditoria do Rio Grande do Sul, SEAUD-RS/DENASUS. As ricas contribuiçôes advindas dessa participação refletem a relevância do cargo exercido. Porém, salienta-se, especialmente, o fato de tratar-se também de um militante de histórica importância no movimento de defesa dos direitos da população negra, com expressivos conhecimentos sobre o tema. Os assuntos por ele abordados envolveram questôes fundamentais para a discussão 
do tema etnia, como a construção social do racismo no Brasil, aspectos históricos, práticas realizadas pelos profissionais de saúde que podem contribuir para a reprodução e manutenção do racismo institucional; princípios básicos da Constituição Federal e algumas sugestôes de açóes para a equipe.

Abordou-se, ainda, o processo de aprovação da Constituição Federal, o papel das políticas públicas para o enfrentamento da discriminação racial, resgate histórico de lutas em que não se reconheceu o protagonismo do povo negro - Revolução Farroupilha, Guerra do Paraguai, Canudos, dentre outras -, algumas formas de disseminação de valores e ideologias que podem ir ao encontro da reprodução do racismo. Esse primeiro encontro contou também com a participação de uma representante da gestão municipal Sra. Glaucia Maria Dias Fontoura, gerência distrital de saúde.

No segundo encontro, com a participação da pesquisadora e da equipe, abordaram-se os seguintes tópicos: retomada dos objetivos do projeto de pesquisa, legislação federal, Plano Municipal de Saúde 20102013, Política de Atenção Integral à População Negra, inserção desta Política no SUS e seus objetivos. Dos objetivos traçados no projeto, pode-se considerar que dois foram alcançados nessa ocasiâo: conhecer as diretrizes e os objetivos da PSIPN e mapear, junto às equipes da ESF, seus principais aspectos a fim de reconhecer suas potencialidades e possíveis lacunas. Considerou-se, na explanação, que cada ente federado tem seu próprio tempo de gestão e execução da Política; por essa razão, citaram-se açóes priorizadas nos níveis federal, estadual e municipal.

O terceiro encontro foi planejado, porém não foi realizado. Estava programada a participaçáo de representantes do movimento de defesa dos direitos da população negra, para o que foram contatados dois grupos. Contudo, os vários esforços envidados no sentido de contar com sua presença na atividade não obtiveram sucesso.

No último, que, de fato, foi o terceiro encontro, realizou-se uma conversa acerca das informaçóes socializadas durante os encontros anteriores a fim de conhecer as possibilidades e limites identificados pela equipe com relação ao tema abordado, relacionando os processos de trabalho atuais e possíveis mudanças que contemplem os aspectos abordados durante os encontros. Também, apresentou-se material didático sobre os aspectos que definem o modo de formular, avaliar e monitorar uma política pública, tomando por base a PSIPN.

\section{Resultados e discussão}

Durante a realização dos encontros previstos na pesquisa, a PSIPN foi conhecida, debatida e, em alguma medida, pode-se dizer que incorporada pela equipe ao final desta pesquisa. Para confirmar esses resultados, serão reproduzidas as falas dos trabalhadores, identificados por siglas, preservando, assim, seus nomes, conforme estabelecido no Termo de Consentimento Livre e esclarecido, do projeto aprovado pelo Comitê de Ética da Escola de Saúde Pública do RS e do Comitê de Ética da Secretaria Municipal de Saúde de Porto Alegre - RS (SMS/PMPA). As siglas usadas são 'TS-trabalhador da saúde', seguidas de números, tendo o resgate das falas ocorrido a partir da gravação dos encontros, conforme previa o estudo.

Com a exposição dos fatos históricos e apontamentos feitos pelo gestor convidado, surgiram importantes reflexóes da equipe, que espontaneamente trouxe para a discussão o cotidiano no serviço, como, por exemplo, o fato de estar ocorrendo uma seleçáo municipal para compor as equipes mínimas na gerência distrital onde se localiza a ESF do estudo. Alguns trabalhadores da equipe inscreveram-se nas cotas, cerca de $30 \%$ da equipe, fato que gerou posicionamentos distintos. Uma das participantes verbalizou "[...] nós negros nos inscrevemos nas cotas e sinto que sofremos pressão aqui” (TS1), no que outra trabalhadora completou:

Eu li um pouco e eu pensei assim: é como se fosse uma divida com o negro, só que a gente não tem noção do que o negro passou e o que reflete hoje na população então a gente pensa assim: não, mas tem branco que sofre a mesma coisa. Mas é uma divida e é a consciência do que ele (o negro) passou e o que hoje ele ainda sofre com isso. Então 
o que se faz: entra com as cotas, que é uma reparação daquilo, daquela injustiça que foi cometida. (TS2).

A fala dessa trabalhadora traz argumentos fortes, que consideram a historicidade das práticas de exclusão, as quais devem ser reparadas por açóes do Estado via políticas afirmativas. Conforme Guimarães:

A luta contra o preconceito de cor transforma-se, nos dias atuais, em luta por açôes afirmativas que garantam maior igualdade de oportunidade de vida para a população negra (GUIMARÁES, 2008, p.113).

Contudo, houve falas discordantes, como, por exemplo: - "E os brancos, ficam onde? (TS3); não é justo, se uma mãe tem um filho negro e outro branco. Só um deles vai ter direito à cota?" (TS3) e outro trabalhador verbalizou: - "Mas temos que atender todos do mesmo jeito, igual. A PNH [Política Nacional de Humanização] já fala de igualdade. Diferenciar pela cor da pele não aumenta o preconceito?” (TS4). Essas falas apresentam a ideia que, ao se considerar especificidades de determinada população, no caso a população negra, poder-se-ia prejudicar outras parcelas da população (os brancos?). Sobre esta concepção Grin defende

\section{[...] a opiniáo pública reconhece o racismo,} mas acredita na miscigenação como evidência do não racismo; [...]; vitimiza o pobre, mas nâo the confere cor; reconhece a perversidade da escravidão, mas não se sente individualmente responsável por qualquer reparação histórica; apoia açóes afirmativas, mas repudia o sistema de cotas raciais (GRIN, 2010, p.89).

Nesse ponto, surge uma questão central relativa ao fato de saber-se que a estratificação social no Brasil tem relação direta com o racismo em razão dos fatos históricos já apontados. Porém, o que determina exclusão e preconceito, muitas vezes, é a cor da pele, o que não está necessariamente vinculado às condiçôes econômicas desfavoráveis, posto que o critério etnia serve como elemento determinante nos processos de exclusão e estratificação social no Brasil (PAIXÃO, 2003). Questóes como os resquícios de um processo de abolição da escravatura, que negou os mínimos direitos econômicos e sociais aos descendentes dos antigos escravos e manteve o regime de propriedade concentrado nas mãos de uma minoria, contribuem para essa realidade excludente (PAIXÃO, 2003). Sendo assim, concorda-se com Grin (2010) quando este afirma que a exclusão social tem no racismo o seu componente mais perverso, pela desigualdade social nele presente.

Em determinados momentos, como na segunda reunião realizada, surgiu novamente a questão da 'diferenciação’ pela cor como possível causadora de prejuízo à população:

\section{A Politica (de saúde) da Populaçáo Negra tem que se inserir na de Humanização (...). Não tem só negro na população periférica. É a ca- rência de suprir a saúde dos mais necessitados" (TS4).}

Não obstante, outra trabalhadora afirmou ter dificuldades para identificar especificidades étnicas, que acredita não se aplicarem aos ciclos de vida, posto que, em sua opinião, são evidentes as particularidades dos ciclos de vida, pois "a cor é natural" e não deve ser diferenciada:

É mais natural a cor do que um idoso, por exemplo. Vou atender um idoso branco ou um preto da mesma forma. Agora, um idoso tem especificidade diferente de um adolescente" (TS5).

Em outra fala, a trabalhadora discordou: - "As politicas se agregam [PNH e PSIPN]. Mas se tu vai pensar só pela ótica da humanização tu esqueces da especificidade" (TS6). A mesma trabalhadora completou: - "Tem que ter um olhar focado na cor, em função de ocupar os piores indicadores sociais, e a gente tá vendo, há diferenças em agravos, doenças" (TS6). Ela referia-se aos indicadores que constam do Plano Municipal de Saúde de Porto Alegre 
2010-2013, apresentado à equipe durante a pesquisa e que revelavam, por exemplo, que, em 2009, os dados de notificação de casos de AIDS apresentavam risco de $1,0 / 100.000$ para a população branca e de 2,5 para população negra, com incidência de 70,6/100.000 para brancos e 175,8 para negros; em relação às gestantes com infecção para o HIV, o risco para as mulheres negras é 2,5 vezes o das mulheres brancas; os homens negros e jovens têm o risco em dobro para mortalidade por homicídio, seguindo a média nacional de outros indicadores.

$\mathrm{Na}$ última reunião com a equipe, debateu-se sobre como uma política poderia ser implantada, ou seja, quais elementos e açóes seriam necessários para implementar a Política de Atenção Integral à Saúde da População Negra, para o qual surgiram diversas sugestôes. Uma delas foi a de inserir o quesito cor nas fichas dos programas - Hiperdia e Pra nenê, inicialmente - a fim de melhor se orientar e constituir um banco de dados mais completo para pesquisas futuras.

A equipe manifestou também a necessidade de debater o assunto etnia com a comunidade, levando a Política ao conhecimento da população, o que demonstrou entendimento da relevância do tema em virtude das especificidades do território. Sugeriu-se, ainda, falar sobre a coleta do quesito raça/cor para a população, usando as reunióes do Conselho Local de Saúde. Todavia, salientaram-se as dificuldades atuais de articulação com a comunidade, que passa por um momento de enfraquecimento da participação no controle social na política de saúde, com poucas lideranças atuantes e participação muito pequena da comunidade: - "Seria bom contar com o controle social, com o conselho local de saúde, né? Pra gente chamar a comunidade, fazer uma reuniāo, mas tá difícil" (TS3).

A necessidade de debater coletivamente o tema etnia envolvendo o maior número de pessoas possível ampara-se na ideia de que esse conceito envolve não somente a cor da pele como também cultura, i.e., aspectos como religião, língua, costumes e modos de vida. Autores, como Marilena Chauí (1986), defendem que cultura não é algo estanque, o que torna indispensáveis os momentos de troca de saberes e construção coletiva já que
Ora, seres e objetos culturais nunca são dados, são postos por práticas sociais e históricas determinadas, por formas da sociabilidade, da relação intersubjetiva, grupal, de classe, da relaçâo com o visivel e o invisivel, com o tempo e o espaço, com o possivel e o impossivel, com o necessário e o contingente. Para que algo seja isto ou aquilo é preciso que seja assim posto ou constituido pelas práticas sociais (CHAUÍ, 1986, p.122).

Outro resultado foram as manifestaçôes dos trabalhadores acerca da coleta do quesito raça/cor segundo o que estabelece o IBGE, embora incentivar a autodeclaração corretamente é responsabilidade do trabalhador da saúde, que deve procurar esclarecer as dúvidas. Sobre as dificuldades que surgem nesse momento foi dito: - "Mas vamos falar como? E se as pessoas se ofenderem? Sei lá, podem achar ruim perguntar assim, a cor" (TS7). E outro verbalizou: - "Mas a gente tem que explicar, dizer os quesitos: citar que moreno não entra e tal..." (TS7), referindo-se à abordagem no momento de coletar a informação. Continuando o debate, alguns trabalhadores sugeriram a atualização de informaçôes dos prontuários, onde não consta o quesito raça/cor: - "As fichas [das familias] antigas não têm informação sobre etnia. A gente poderia atualizar os prontuários, começando sei lá, pelo bloco um ou o treze" (TS4). Outro trabalhador concorda: - "Pode ser. Vamos fazer isso com todos de um bloco que forem atendidos, depois a gente vê como foi" (TS6) - Importante esclarecer que o território da ESF da qual trata a pesquisa tem seu território dividido em treze blocos e que a escolha da equipe pelo bloco um foi aleatória.

Estabeleceu-se, entáo, que a coleta do quesito raça/cor seria realizada com as pessoas atendidas do bloco um, com as quais se falaria a respeito da questão étnica, explicando os quesitos do IBGE e suas justificativas para coletar a informação. Surgiu, assim, um projeto piloto de implementação da Política a partir da atualização dos dados dos prontuários, das conversas individuais durante as consultas e nas salas de espera, e combinou-se que a avaliação desse processo realizar-se-ia em dois meses, em reuniáo de equipe, dentro do tempo reservado para educação permanente. 
A avaliação do projeto piloto foi retomada em outros momentos, durante as reunióes da equipe. Relatou-se que houve maior incidência de conversas a respeito do tema no momento do acolhimento. Durante as consultas, conversou-se, por vezes, com a população, mas a equipe considerou pouco o tempo que se dispunha na consulta para que se pudesse refletir sobre o tema etnia e abordar demandas de saúde. Atualmente, os integrantes da equipe têm conversado com a população a respeito do tema durante os atendimentos, realizando-se a coleta do dado a partir da autodeclaraçáo. Ainda não é uma prática frequente, mas o tema etnia tem sido abordado, o que representa um avanço.

\section{Comentários}

A discussão acerca da temática etnia ganhou força nas últimas décadas no Brasil, guardando estreita relação com ações adotadas pelo governo federal nos anos 2000. Uma importante conquista foi a criação, em 2003, da Secretaria de Políticas de Promoção da Igualdade Racial, cuja finalidade é atuar na formulação, coordenação e articulação de políticas e diretrizes de diferentes ministérios, dentre os quais o da saúde, e outros órgãos do governo brasileiro para a promoção da igualdade racial.

Quanto à pesquisa realizada, pondera-se que os resultados mais importantes foram coletados nas discussóes mantidas com a equipe e nas possibilidades de mudança de concepção, além das conversas realizadas com a população, ainda que de forma pontual.

Outro resultado importante foi a demonstração de interesse sobre o tema por parte de alguns trabalhadores, que se sentiram motivados a dar continuidade às discussóes com a equipe. Esses trabalhadores têm participado de eventos que tratam do assunto etnia e propóem-se a dar continuidade a açóes tais como conversas com os usuários que aguardam pelo atendimento - agendado ou não - do dia, a fim de prestar informaçôes e esclarecer dúvidas.

A pesquisa cumpriu seus objetivos, criando uma abertura para o diálogo e para o conhecimento da PSIPN, mesmo que ainda esbarre em limitadores. Iniciar o processo de implementação de ações que contemplem a Política por meio da discussão com os trabalhadores dos serviços é uma estratégia potente para que se pactuem as mudanças necessárias à qualificação do atendimento. A partir da compreensão da equipe sobre a importância do recorte racial, possibilitou-se criar as condiçōes para identificar as reais necessidades da população segundo suas especificidades. Assim, essas informaçôes poderão ser empregadas como critério de planejamento e definição de prioridades. Essa é também uma forma de combate ao racismo institucional, e marca da PSIPN - política direcionada à sociedade em geral -, posto que qualquer sujeito pode praticar o racismo, independentemente de sua etnia e que

Qualquer discriminação é imoral e lutar contra ela é um dever por mais que se reconheça a força dos condicionamentos a enfrentar. A boniteza de ser gente se acha, entre outras coisas, nessa possibilidade e nesse dever de brigar (FREIRE, 1996, p.61).

Logo, a luta contra a discriminação racial é dever dos cidadãos, e a efetivação da Política de Atenção Integral à saúde da População Negra é uma tarefa a ser executada por todos os trabalhadores inseridos no SUS, de forma a que se contribua para a supressão do preconceito e do racismo institucional nos serviços de saúde.

\section{Referências}

ABREU, N.P. (Org.). Constituição Federal: promulgada em 05 de outubro de 1988. 2. ed. Porto Alegre: Verbo Judiciário, 2001. sobre Determinantes Sociais da Saúde. Disponível em: <http:// www.determinantes.fiocruz.br/>. Acesso em: 10 dez. 2012. 
da População Negra. Brasília, 2007. Disponível em: <http://bvsms. saude.gov.br/bvs/publicacoes/politica_nacional_saude_populacaonegra.pdf>. Acesso em: 03 ago. 2012.

CHAUI, M. Conformismo e Resistência: aspectos da cultura popular no Brasil. São Paulo: Editora Brasiliense, 1986.

FERNANDES, F. A integração do negro na sociedade de classes. 5. ed. São Paulo: Globo, 2008.

FREIRE, P. Pedagogia da autonomia: saberes necessários à pratica educativa. São Paulo: Paz e Terra, 1996.

GRIN, M. Raça: debate público no Brasil (1997-2007). Rio de Janeiro: Mauad X: FAPERJ, 2010.

GUIMARÃES, A.S.A. Preconceito racial: modos, temas e tempos. São Paulo: Cortez, 2008.

HAGUETTE, T.M.F. Metodologias Qualitativas na Sociologia. 2. ed. Petrópolis: Vozes, 1992.

INSTITUTO DE PESQUISA ECONÔMICA APLICADA (IPEA) [internet]. Comunicados do Ipea n. 91 - Dinâmica Demográfica da População Negra Brasileira, 2011. Disponível em: <http://www.ipea.gov.br/ portal/images/stories/PDFs/comunicado/110512_comunicadoipea91.pdf>. Acesso em: 03 ago. 2012.

JACCOUD, L. O debate sobre o branqueamento e a discriminação racial no Brasil. In: THEODORO, M. (Org.). As políticas públicas e a desigualdade racial no Brasil: 120 anos após a abolição. Brasília: IPEA, 2008.

KERKHOFF, C.; FOLA, N. Conversa Afiada: Estratégia de Saúde da Família e Comunidade Terreira de Ilê Asé lyemonjá Omi Olodô. In: PORTO ALEGRE. Secretaria Municipal de Saúde. Olhares sobre a equidade em saúde. Porto Alegre: Secretaria Municipal de Saúde, 2012.
MINAYO, M.C.S. et al. (Org.). Pesquisa Social: teoria, método e criatividade. 21. ed. Petrópolis, RJ: Vozes, 2002.

PAIXÃO, M.J.P. Desenvolvimento humano e relações raciais. Rio de Janeiro: DP\&A, 2003.

PORTO ALEGRE. Secretaria Municipal de Saúde. Plano Municipal de saúde 2010 -2013. Disponível em: <http://lproweb.procempa. com.br/pmpa/prefpoa/sms/usu_doc/pms.pdf>. Acesso em 13 out. 2011.

RODRIGUES, S.D.P. Participação no primeiro encontro com trabalhadores da unidade de saúde para a realização da presente pesquisa. Material de áudio e vídeo (DVD) gravado em POA em 10.05.2012.

THIOLLENT, M. Metodologia da pesquisa-ação. 4. ed. São Paulo: Cortez, 1988.

THIOLLENT, M. Metodologia da pesquisa-ação. 11. ed. São Paulo: Cortez, 2002.

THEODORO, M. (Org.). As políticas públicas e a desigualdade racial no Brasil: 120 anos após a abolição. Brasília: IPEA, 2008.

Recebido para publicação em julho de 2013

Versão final em dezembro de 2013

Conflito de interesse: não houve

suporte financeiro: inexistente 